\title{
Algumas relações entre design, espaço e mediação
}

Fátima Aparecida dos Santos é Designer (Unesp 1997), Mestre (2001) e Doutora (PUCSP- Comunicação e Semiótica 2007). Estágio pós doc Università Degli Studi di Torino, CIRCE- Centro Interdipartimentale di Ricerca sulla Comunicazione sob supervisão do prof. Mássimo Leone. Professora do Departamento de Design/ Instituto de Artes da Universidade de Brasília. Professora Permanente do PPGDesign na linha de Design Espaço e do PPG Artes Visuais na linha Mediação e Imagem Visualidade e Urbanidade. <designerfatima2012@gmail.com> ORCID: 0000-0003-1009-8235
Resumo A linha de pesquisa Design, Espaço e Mediações, vinculada ao PPG Design da UnB, propõe reflexões voltadas ao cotidiano e à configuração do espaço compreendendo seus aspectos culturais. Considera-se o campo do design em fricção com territórios, com os modos de vida e ações políticas. Os aspectos culturais e ecológicos são base para estudos do design enquanto linguagem. Pensa-se a cidade em sua multiplicidade de territórios, também como espaço construído e imaginado, lugar da cristalização de velhos modelos e hábitos, no qual reside a disponibilidade para o sonho, a inovação, a utopia, abordados na linha a partir das fricções entre poética, design e espaço urbano. Considera-se ainda o papel educativo de tal linguagem modelar, as diversas possibilidades de informar disponíveis na urbe e que podem ser potencializadas por artefatos de design. Assim pretende-se uma cidade cujos artefatos de design, sistêmicos, formais, sinaléticos busquem o processo de emancipação e coparticipação educativa.

Palavras chave Design, Território, Educação, Espaço, Escritura. 


\section{On relations between design, space and mediation}

Marisa Cobbe Maass é Professora do Departamento de Design da Universidade de Brasília desde o ano 2000 e Pesquisadora no PPG Design desde 2013, atuando na linha de pesquisa Design, Espaço e Mediações. Graduada em Arquitetura e Urbanismo, Mestre em Teoria e História pela UnB e Doutora em Teoria, história e Crítica, com estágio na Universidade de Paris 1, Sorbonne. Concluiu o Pós-doutoramento no Núcleo de Educação Artística, do Centro de Investigação em Artes e Design e Sociedade na Belas Artes da Universidade do Porto em 2017. Lidera o Grupo de Pesquisa Design Educação desde2017.>mmaass@unb.br>

ORCID: 0000-0001-7640-9927

Rogério Camara é Graduado em comunicação visual pela Pontifícia Universidade Católica do Rio de Janeiro (1990), mestre em Comunicação pela Universidade Federal do Rio de Janeiro (1999) e doutor em Comunicação pela Universidade Federal do Rio de Janeiro (2004). Professor da Universidade de Brasília. Tem experiência profissional nas áreas de Design e Educação. Participa como docente do Programa de Pós-graduação em Artes e do PPGDesign, ambos da Universidade de Brasília. Realiza pesquisas sobre as relações entre escrita e cidade com ênfase na poesia visual e nas novas tecnologias. <rogeriojcamara@gmail.com> ORCID: 0000-0002-1590-4948
Abstract The research area Design, Space and Mediations, linked to the Postgraduate Program in Design of the University of Brasilia, proposes reflections on daily life and the configuration of space understanding its cultural aspects. The field of design is considered in friction with territories, with lifestyles and political actions. Aspects of cultural and ecological systems are the basis for studies on design as language. The city is thought on its multiplicity of territories, also as a constructed and imagined space, place of crystallization, old models and habits, in which lies the availability for dream, innovation, utopia, addressed in the research area by frictions between poetics, design and urban space. The educational role of such language mould is considered, as well as the different possibilities of information available in the city, that can be enhanced by artifacts. Thus, cities are viewed with its design artifacts, as a systemic, signaling and formal structure, seeking the process of emancipation and educational co-participation

Keywords Design, Territory, Education, Space, Writing.

\section{Algunas relaciones entre diseño, espacio y mediación}

Resumen La línea de investigación Diseño, Espacio y Mediaciones, vinculada al Programa de Posgrado en Diseño de la Universidad de Brasilia, propone reflexiones centradas en la vida cotidiana y la configuración del espacio, incluyendo sus aspectos culturales. El campo del diseño se considera en fricción con los territorios, con las formas de vida y las acciones políticas. Los aspectos culturales y ecológicos son la base de los estudios del diseño como lenguaje. La ciudad es pensada en su multiplicidad de territorios, también como un espacio construido e imaginado, un lugar de cristalización de viejos modelos y hábitos, en el que reside la disponibilidad para el sueño, la innovación, la utopía, abordada en la línea de las fricciones entre poética, diseño y espacio urbano. También se considera el papel educativo de dicho lenguaje modelo, las diversas posibilidades de información disponibles en la ciudad que pueden ser potenciadas por artefactos de diseño. Así, se pretende una ciudad como una estructura sistémica, señalizadora y formal, buscando el proceso de emancipación y coparticipación educativa.

Palabras clave Diseño, Territorio, Educación, Espacio, Escritura. 


\section{Introdução}

Em sua descrição, a linha de pesquisa Design, Espaço e Mediações, vinculada ao PPG Design da UnB, se propõe a reflexões sobre o papel do design para a compreensão dos mecanismos constitutivos do espaço, dos processos de transformação dos hábitos. A linha se volta às questões fundamentais do campo da cultura pela mediação tecnológica, social, comunicacional, artística e analisa os desafios da introdução de suportes, canais e modelos de mediação para o exercício ativo da cidadania. Para tanto, vem sedimentando, nos últimos anos, pesquisas voltadas às trocas culturais e à lógica de organização, assim como à criação, produção e pensamento sobre diversas formas inscrições e cartografias urbanas. Considera-se o campo do design em friç̧ão com o território, com os modos de vida e ações políticas, o que implica sobre o hábito, sua generalização e mecanismos de emergência, o que toca a semiótica em sua vertente pragmática.

Neste texto, apresenta-se a confluência das pesquisas sobre Design, Espaço e Mediação especificamente pelo viés da Semiótica da Cultura, dos processos comunicacionais e da relação entre Poética, Estética e Educação. Criar artefatos para a vida, sejam eles em quais linguagens e processos forem, provoca uma modelização no espaço, cria territórios e pertencimentos.

Os aspectos culturais e ecológicos são base para estudos do design enquanto linguagem. Pelo prisma semiótico é possível afirmar que criar artefatos para a vida, sejam eles em quais linguagens e processos forem, provoca uma modelização no espaço. Aqui, entende-se a linguagem como sistema estruturado de signos e o termo modelização, a partir da perspectiva da semiótica da cultura:

A cultura como um sistema baseado, em última análise, em uma língua natural (é o que significa o termo "sistemas modelizantes secundários", que contrasta com o "sistema primário", isto é, a língua natural) pode ser considerada como uma hierarquia de sistemas semióticos que se correlacionam em pares. Essa correlação entre eles se realiza, em grande medida, por meio da conexão com o sistema da língua natural. (MACHADO, 2003, p. 123)

Assim, os aspectos culturais e ecológicos são a base para estudos do design enquanto sistemas de signos que geram semioses e de algum modo modelizam e são modelizados. Neste sentido, talvez em uma perspectiva histórica, o que se poderia pontuar como uma adaptação ergonômica e cognitiva de signos e objetos em uma perspectiva semiótica realiza-se por meio da semiose de signos no espaço, a forma, além de seguir a função, gera uma cadeia de semioses que delineia outras formas e funções num processo espiral que permite pensar a cidade enquanto camadas acentradas de processos signos disparados por diferentes agentes e forças. 
Pensa-se a cidade em sua multiplicidade de territórios e de agenciamentos. A cidade como espaço construído e persistente, mas também imaginado, lugar da cristalização de velhos modelos e hábitos, no qual reside a disponibilidade para o sonho, a inovação, a utopia. Procura-se observar, por processos abdutivos, sistemas de signos capazes de compreender os espaço de vida e suas relações.

Nas investigações empreendidas, o território pode ser considerado como o lugar da ação individual ou como o lugar da ação do grupo. Em Agamben (2013. 2015), Gibson (1985) e Uexkull (2004) o termo território define o lugar no qual determinado ser vivo consegue estabelecer sua linha de influência, de ação, de crítica e, portanto, de modelação, transformação e pertencimento. Sendo assim um dado espaço pode conter diversos territórios agenciados por diversos grupos que podem ou não dialogarem, permitindo a emergência de choques culturais, de enfrentamentos linguísticos modelizando comportamentos, comunicações e a produção de artefatos.

A questão utópica é abordada na linha a partir das fricções entre poética, design e espaço urbano. A poesia e arte visual como potência para influenciar novas leituras, percepções e usos da cidade, mas que pode ser observada em ações de diversos coletivos no Brasil.

Considera-se ainda o papel educativo de tal linguagem modelar, as diversas possibilidades de informar disponíveis na urbe e que podem ser potencializadas por artefatos de design. Segue-se, portanto, o entendimento da cidade e seus territórios a partir de uma dialética educacional e política. Defende-se o papel da comunicação para a educação, saltando de uma educação voltada à recepção para um projeto de educomunicação coparticipante e dialético. Assim pretende-se uma cidade cujos artefatos de design digitais, visuais, sistêmicos, formais, sinaléticos busquem o processo de emancipação e coparticipação educativa.

A linha de pesquisa Design, Espaço e Mediação se viu potencializada em função da localização da Universidade de Brasília, componente da cidade de Brasília desde o projeto de Lúcio Costa. A relação entre a vida ordinária desenvolvida sob o experimento mais ambicioso em termos de urbanismo de toda a história do Brasil, resultando em formalismo científico e planejamento funcionalista, torna-se um arcabouço inesgotável de objetos de pesquisa. As modelizações ocorridas do urbano para a cidade, da cidade para os territórios e a mediação destes por meio dos processos criativos e metodológicos do design podem contribuir na construção de conhecimento neste campo.

Em 2017 Brasília tornou-se Cidade Criativa do Design, reconhecimento dado pela UNESCO. O que gera um questionamento de partida, capaz de influenciar o campo de investigação de pesquisadores em design e áreas correlatas: como uma cidade pode ser espaço de criação em maior ou menor grau? o que faz de uma cidade uma cidade criativa? Tal resposta pode residir no entendimento da relação entre permanência e liberdade em determinados sistemas semióticos. Um sistema semiótico se faz diante de processos de modelização bem como semioses promovidas pelos proces- 
sos de mediação entre signos componentes de tal sistema. Tal explicação embora calcada no pensamento semiótico é também aplicável aos sistemas compostos por artefatos de design. É como a fina relação de influência que permite que o projeto das estradas e ruas comunique e forneça elementos para o design dos meios de transporte e automóveis e, esses por sua vez, interfiram também no espaço interno de veículos bem como design das paradas de ônibus. Tal sistema constitui um feixe de linguagens e modelizações de elementos de design.

\section{Cidade como sintaxe, cidade como feixe...}

A cidade como mídia, como discurso, como paisagem, como suporte para a discussão literária, ou ainda, a cidade como metáfora, fez e faz parte dos estudos do design, da arquitetura, da comunicação e dos estudos Semióticos. De Benjamin (2012) à Lotman (2000), passando por Simmel (2005), das discussões teóricas iniciais às atuais, é, por excelência, no espaço urbano que os jogos sociais e culturais desenvolvem seus processos e, portanto, acontecem.

Walter Benjamim e George Simmel falam de percepções e modelizações em cidades, ambos versam sobre um outro tempo, mas cujos desafios continuam sendo enfrentados ainda hoje. Se o Flaneur (BENJAMIN, 2012, p. 654) era o sujeito que se sentia esvaziado de função estética e política e a quem restava o espetáculo da praça pública, das multidões e o entorpecimento das vitrines, hoje tem-se os Flaneurs que vagam pela cidade sem a percepção da sua concretude guiados por artefatos digitais mediando o contato com o ambiente, mas também reduzindo as possibilidades de encontros sensíveis.

O estar sozinho na multidão de Benjamin, imortalizado na figura do Flaneur da poesia de Baudelaire, é em uma aproximação literária com o texto escrito décadas antes por Simmel (2005, p.579), resultado de um distanciamento, automatização e objetividade presentes no espaço urbano ocorrido em função do afastamento produtor x consumidor. Simmel (op. cit) pergunta onde as pessoas indagam sobre a sua interioridade na cidade, onde o corpo da cultura indaga sobre a sua alma?

Portanto esse feixe de linguagens e mediações a que se nomeia como cidade é também uma força coercitiva sobre comportamentos livres, Simmel (2005, p. 580) afirma que caso todos os relógios de Berlin se desarranjassem, gerando atrasos variados, por algum motivo, tais diferenças ainda que em poucos segundos geraria um caos tão grande na cidade se expandiria como uma cadeia trágica de acontecimentos por muito tempo. Assim o tempo é um fator de modelização da cidade e dos projetos que fazem dela palco da sua existência e expressão.

A cidade se constitui do engendramento dos seres e mecanismos que vivem e interferem nela. Viver em uma cidade é sujeitar-se ao seu tem- 
po, aos seus faróis, ao controle de tráfego. Sistemas como o Google maps precisam o tempo de deslocamento a partir dos elementos que definem a mecânica da cidade e dos registros de hábitos pessoais.

Assim, a cidade que é objeto de estudo de geógrafos, sociólogos, urbanistas, antropólogos e ecologistas deve ser defendida também como campo de estudo do Design. Defender que as pesquisas em design podem ter a cidade como objeto e tem exigido esforço, empenho e coragem, uma vez que a tal transdisciplinaridade não é bem vista nem aceita nos principais veículos de comunicação científica.

As pesquisas em design no Brasil sofrem desde a implantação da primeira graduação da área na década de 60 a influência das práticas anglo-saxónicas de pesquisa que preconizam a investigação a partir de modelos controlados com a expectativa de validação de resultados conformados com bases estatísticas sólidas. Já a cidade escapa de tal método porque tem uma complexidade que por vezes é impossível de ser reduzida a um modelo de laboratório. Mesmo a cidade de Brasília construída sob a égide funcionalista hoje não pode mais ser pensada a partir de laboratórios. Por isso, na linha Design, espaço e mediação, parte das pesquisas tem como aporte teórico a semiótica da cultura. Tal fundamentação parte da premissa que só a experiência em campo, com pleno funcionamento de todos os elementos constituintes, permite aproximação com o fenômeno a ponto de superar configurações apriorísticas ou mesmo impostas por força da autoridade de determinado método.

Assim, a dificuldade de se ter a cidade enquanto objeto de estudo semiótico reside no fato de ela não ser redutível a um único sistema, a uma única matriz geradora de textos. A cidade se estabelece como um feixe de textos complexos no qual eixos, coordenadas e abscissas se inter-relacionam para dar os aspectos e leituras que possíveis do ambiente urbano.

A cidade não pode ser considerada como um palco livre, isento ou como um ponto zero da história, é um cenário no qual diversas narrativas se desenvolveram, geraram informações, textos e cultura, que corroboram para os acontecimentos atuais e futuros. Pensar os sistemas urbanos requer o esforço de entender a cidade como o resultado de fluxos de pessoas e os mecanismos de geração de significados presentes em tais fluxos migratórios (cultura, vocabulário, vestimenta, gestos e por quê não na linguagem verbal?). Os fluxos migratórios por sua vez também geram tensões, confrontos semióticos de partida como a definição de línguas oficiais.

Portanto, sabe-se que as investigações pretendidas na linha Design, Espaço e Mediações não se limitam a um horizonte imediato com resposta pronta, pelo contrário, instigam os pontos já elencados e os ampliam ao se considerar a eleição da cidade como o espaço no qual as dinâmicas, os processos e as representações acontecem. A diferença do estudo proposto é, portanto, considerá-lo diante das conexões e complexidades passíveis de mapeamento. Mais do que mapear pretende-se uma cartografia dinâmica, capaz de inserir a questão também do tempo ou dos vários tempos deste espaço. 
Quando uma cidade perde a sua capacidade de manter e atrair pessoas ela deixa de existir. Assim, a palavra manter, abre caminho para a inserção da palavra tempo, o tempo de permanência das pessoas sobre aquele espaço é o elemento chave para compreender como ele ganhará significado. Em outras palavras é a expectativa de permanecer que gera a força motriz para transformar um espaço em ambiente qualificado e tal qualificação é a geradora de significados para um grupo. Outro elemento chave é que tal qualificação do espaço que o transforma em ambiente se dá pelos modos de operação presentes nos sistemas semióticos urbanos.

Os sistemas semióticos urbanos são aqueles que traduzem ou auxiliam na transcodificação do espaço urbano. Eles estão dispostos em vários níveis conforme o envolvimento e imersão do usuário da cidade, são artefatos em linguagem formal, digital e visual porque é neste fazer que reside a expertise da construção de interfaces e portanto, do design. Os sistemas arquitetônicos, de sinalização, os mobiliários urbanos, os games sobre cidade, as redes cidades inteligentes são exemplos de como tais fazeres são conjuntos e sistemas de signos que permitem interpretar e entender determinado espaço, participar ou ser repelida dele.

Quando se pensa em como os sistemas semióticos urbanos são necessários para abarcar a criação, observa-se que o mecanismo de se abrir e se fechar para as informações, gera a proteção de determinadas estruturas que emergem ou explodem quando friccionadas por um florescimento econômico ou social. Em Brasília, começa-se a perceber tal funcionamento a partir do tombamento do chamado Plano Piloto e os enfrentamentos decorrentes dessa proteção. Em 2008, por exemplo, ouve um embate sobre a instalação ou não de uma cerca de proteção em meio ao Eixo Norte-Sul, via expressa que corta a cidade de uma extremidade a outra, e tem velocidade de $80 \mathrm{~km}$ por hora. Em vários pontos dessa via tem ocorrido atropelamentos e mortes de pedestres que insistem em atravessar mesmo com a alta velocidade dos veículos. Mesmo diante de tamanha tragédia não foi possível agregar elementos de proteção ao pedestre à via em função do tombamento.

Em outras cidades é possível observar a cidade alegórica sobreposta por mecanismos informacionais e sistemas de transportes. Veneza, a despeito de toda diversidade e fluxo, tem um sistema de transporte organizado. A cidade sobrepõe aos velhos canais a força de um diagrama pelo qual de forma lógica navegam as barcas que compõem o sistema de transporte público. Trata-se de um feixe de designs que agrega bilheterias, bilhetes, plataformas flutuantes, barcas, barqueiros, anúncios internos, sistema de informação digital com previsão justa de horários em cada plataforma. E o sistema de transporte é um dos componentes da cidade no qual se observa a conexão entre a cidade alegórica, tombada e as necessidades contemporâneas. Em outra camada, na mesma Veneza, uma simples caminhada revela textos que foram escritos em um outro tempo, diante de outros desafios e que realmente sobreviveram no tempo e no espaço porque conseguiram manter seus significados ou ser suporte de novas informações. Quando se olha para o diagrama disponível no sistema de transporte em Veneza (San- 
ta Lúcia, San Marco, etc.) percebe-se uma fusão do tempo, os velhos canais, as gôndolas e seus gondoleiros, os velhos palacetes com diferentes informações sobre o nível das águas, convivendo com rotas específicas das barcas que carregam passageiros e levam para a ilha tanto em percurso quanto em tempo o funcionamento das linhas de metrô presentes em qualquer grande cidade do mundo. Neste caso é o presente, que um dia foi futuro, interferindo numa estrutura alegórica de passado.

Trata-se de um jogo temporal estabelecido na atualidade mas que permite, através dos signos disponíveis em um dado espaço, navegar no tempo e nas intenções dos autores dos textos arquitetônicos urbanos, isso acontece também em Brasília, apesar da janela temporal menor, se consegue perceber como, por vezes, existe um saudosismo em relação ao passado, neste caso, de novo tais heterotopias levam não somente para a percepção de como o presente foi planejado ou pensado no passado, mas também como o passado emerge como texto cultural contemporâneo.

As pontuações e exemplos em Brasília e em Veneza permitem pontuar brevemente neste artigo de apresentação algumas premissas das pesquisas que relacionam o design, a cidade, as mediações possíveis e a semiótica como uma das mediações trabalhadas na linha de pesquisa. Continuando ainda com o argumento do design como feixe de linguagens, outro paradigma defendido na linha de pesquisa é a construção de uma investigação no qual o design é tratado como princípio mediador da educação estética.

\section{Design e educação estética}

Entende-se design como algo maior e mais complexo do que o traçar linhas sobre o papel. Trata-se da articulação de feixes de linguagens que devem abrir e manter um diálogo com o palco onde ele acontece: a cidade, tendo como articulador o usuário e promovendo assim uma ação dialética, emancipadora, educativa e propositiva de novas possibilidades de viver.

Esta articulação induz a reflexões acerca da inclusão de conteúdos de design na formação de professores do Ensino Básico Público brasileiro (fundamental e secundário), tendo como ponto de partida as possibilidades de interfaces entre as artes visuais e o design que ocorrem nas disciplinas de artes visuais, com um recorte direcionado ao ensino secundário.

A formação de professores traz desafios cada vez maiores em face dos avanços tecnológicos e das mudanças pelas quais as gerações estão experimentando, cada vez mais rápidas, nas últimas quatro décadas, onde o modo de viver, a relação com a natureza, o tempo de vida, e referências culturais basilares foram alteradas. (SERRES, 2012) O design surge como um campo de observações muito rico em vista da sua ubiquidade e transversalidade, e cerca a todos que vivem no meio urbano. Interage com as outras áreas tanto das artes e da cultura, quanto de física, matemática, biologia, ecologia e outras. Algo muito sedutor, para os professores e estudantes. 
Basta olhar para o lado e já se tem material de estudo: objetos e sistemas que trazem em si valores de diversas naturezas. $O$ ambiente que promove "a 'intimidade' entre os saberes curriculares e a experiência social que os educandos têm como indivíduos" (FREIRE, 1996,p.30).

Ao lado disso, o design tem o poder de transcender os aspectos prático-necessários e adentrar a esfera do artístico. E que mundo é esse que a obra de arte instaura? É o mundo da imaginação. Da riqueza interior e das experiências vividas de cada um. Um mundo de diálogos reflexionantes.

Uma obra de arte precipita a reflexão sobre a vida. Sobre a vida do próprio homem. Produz momentos de promessa. Uma das noções que Paulo Freire discute no seu livro Pedagogia da Autonomia é a noção de inacabamento do ser: 0 ser humano como alguém que está em constante processo de invenção e reinvenção de si mesmo. E a educação pela arte é uma oportunidade, uma janela que se abre nesse processo. 0 educador está no papel de estimulador de descobertas. Paulo Freire formulou a pedagogia da autonomia, em um contexto de educação de jovens e adultos e alfabetização de adultos, no Brasil, na década de 70. Freire propõe o diálogo a partir das subjetividades. Ele afirma: "A autonomia torna o sujeito alguém capaz de transformar sua própria existência. De recriar-se."

Também neste espaço, surgido da lacuna entre design e artes visuais, que observamos existir um campo de reflexão importante.

Heiddegger, em A origem da obra de arte, fala sobre a experiência estética: "A obra de arte instaura um mundo". O mesmo pode-se dizer do valor estético do design que cria a oportunidade do diálogo, da intersubjetividade, da convivência. Estar diante de uma obra poética, faculta o encontro, a troca, o compartilhamento de olhares. Os utensílios, apesar da sua vocação para o uso, têm um potencial que extrapola a funcionalidade (WILLIAMS, 2009). A partir da prioridade que é dada aos aspectos na constituição do objeto, "em certos projetos, o que ocorre, é que o componente artístico fica tão grande em relação aos outros que passa a dominar a percepção que o sujeito faz do objeto" (BOMFIM, 1998: 16).

O foco aqui é principalmente a experiência estética e como esta experiência pode se dar trabalhando com suportes em design e artes visuais em diálogo. Interessa discutir a importância da formação de um olhar reflexivo voltado para a construção da autonomia, com o rebatimento da dimensão estética como fator qualificador, ou seja, fator de emancipação. Questão relacionada com o papel fundamental da arte como eixo aglutinador, permeando o dia a dia do cidadão, e no nosso caso, do estudante, para quem, muitas vezes o repertório dos museus está demasiado desconectado da sua realidade, principalmente no Brasil, um país com tantas desigualdades sociais e onde ainda existem museus restritos, na sua maioria, aos grandes centros. O Brasil é um país que valoriza pouco seu patrimônio histórico/ artístico/ cultural. Portanto, faz-se necessária a visão da importância da educação estética como estrutura para a leitura poética de mundo sem depender de tutela, ampliando a capacidade de expressão artística, de reinvenção de si mesmo, do sonho e da proposta de um mundo novo. Sob 
esta ótica, Clement Greenberg afirma que: "Ao transcender a esfera pessoal, a arte e o gosto não se apartam consequentemente da 'vida', do restante da experiência, ou seja, da experiência não estética. A ampliação e o aprimoramento continuado do gosto de um indivíduo em qualquer direção demandam - ao que parece - que ele amplie e aprimore seu sentimento pela vida de modo geral" (GREENBERG, 2002,p.59).

A atitude estética, no contexto da formação, instaura no sujeito a consciência da alteridade. Essa consciência se dá na partilha do sensível, que é o papel da estética. Isso acontece precisamente nos momentos de diálogo que surgem a partir da experiência estética que disparam processos de reflexão e se tornam valiosos momentos para o aprendizado humanístico. E a instalação deste ciclo é o grande fator motivador da ampliação continuada do gosto. Esta ampliação traz um crescimento das possibilidades de identificação e apreciação do artístico no cotidiano e aproxima os objetos passíveis de um olhar crítico, afirmando a presença da poesia nos mais variados contextos.

A educação estética é parte importante na criação de uma consciência política, consciência cidadã, porque traz consigo o conceito de compartilhamento. Reciprocidade. Ajuda a entender os mecanismos que expressam o coletivo e o particular e as diferenças entre essas instâncias, e a possibilidade de interagir com o mundo, cientes do seu papel social. A democracia é construída com pessoas que têm essa consciência. Esses valores estão na base da formação, para que os atores possam efetivamente agir em sociedade com essa consciência da importância do trabalho para o bem coletivo. Carlos Vergara fala sobre o papel do artista, que é o de transformador de olhares prosaicos em olhares poéticos. No universo da escola, o professor faz esse papel. (2009)

No Brasil, em relação à legislação, o design encontra-se contemplado nas documentações do Ministério da Educação, como conteúdo associado ao ensino das artes. (LINGUAGENS Códigos e suas Tecnologias, 2008)

o fato de não haver formação para os professores do ensino básico nesta área faz com que este passo, que já tinha sido dado em termos de legislação, não se concretize na prática de modo pleno e traz como consequência a ausência de professores de ensino médio com esta formação específica.

Assim, existe uma expectativa e uma possibilidade de atuação, mas não existe a formação correspondente para os professores hoje no Brasil.

Os professores do ensino básico e médio no âmbito das artes têm formações específicas apenas nas áreas de Artes Visuais, Música e Artes Cênicas.

As escolas superiores de design, tem sua formação fortemente direcionada para a tecnologia e formação profissionalizante (bacharelado) direcionada para a atuação no mercado. (COUTO, 2008)

Existem algumas raras exceções de professores de artes visuais que tem o curso de bacharel e design com dupla formação em Artes Visuais Licenciatura e que optam pela docência para obter uma estabilidade financeira que os estúdios não dão. 
Apesar disso, os professores de ensino médio, utilizam muitos conceitos e conhecimentos específicos de design nas suas aulas, pela atualidade e apelo que o design exerce, baseando-se em conhecimentos adquiridos fora dos cursos de formação de professores (formalmente ou não). 0 design historicamente tende a assumir esse papel de agente catalisador para reunir arte, tecnologia e ciência.

\section{Considerações Finais}

Neste texto foram apresentados dois eixos paradigmáticos das pesquisas desenvolvidas na linha Design, Espaço e Mediação. Atualmente a linha conta com cinco pesquisadores e, além dos eixos apresentados, considera: as questões sociológicas advindas da relação entre cidade, projeto, tombamento e contemporaneidade; Os territórios formados pelas inscrições urbanas e as poéticas que se derivam a partir de tais gestos, implicando em criações utópicas e distópicas, trabalhando com pontos de influência e linhas de fuga nos processos de "fazimento", para usar um termo de Darcy Ribeiro; Os imaginários urbanos suscitados pela cidade e sua atmosfera, às percepções dos grupos sociais dos territórios que compõe a cidade bem como quais vias e formas tais percepções têm para se expressar; Por fim, as mediações e as redes sociais que desenham a cidade virtual e seus desdobramentos físicos também são abordadas.

Desde o surgimento do Programa de Pós-Graduação em Design da Universidade de Brasília observou-se a força e a necessidade da existência de uma linha de pesquisa que desse conta das fricções ocorridas em uma cidade com expressões e modos tão particulares quanto Brasília e ainda como estar neste lugar, neste momento histórico, impacta e permite gerar conhecimento em design.

$\mathrm{Na}$ primeira configuração do programa a abordagem de tal tema estava difusa entre as duas linhas de investigação, Design de Informação e Design Sociedade e Cultura. Após a avaliação do primeiro quadriênio, implementou-se a organização de fóruns de discussão nos quais foi observado que tanto as pesquisas docentes quanto discentes apresentavam forte aproximação com as questões relacionadas ao Design enquanto mediador do espaço urbano, dos diversos territórios manifestos neste e, portanto, da formação disso que se reconhece como cidade. Assim, foi possível reorganizar o Programa de Pós-Graduação, aglutinando em uma só linha as pesquisas que tinham seus eixos norteadores direcionados para a cidade, os processos de mediação, de emancipação e o olhar para um conjunto de fatores que operem como promotores de bem-estar sendo os territórios que compõe a cidade os palcos nos quais tais processos se manifestam. 


\section{Referências}

AGAMBEN, Giorgio. O aberto: o homem e o animal. Rio de Janeiro: Civilização Brasileira, 2013. AGAMBEN, Giorgio. Meios sem fim: notas sobre a política. Belo Horizonte: Autêntica editora, 2015.

BENJAMIN, Walter. Charles Baudelaire: un poeta lirico nell'età del capitalismo avanzato. Cura di Giorgio Agamben, Barbara Chitussi, Clemens-Carls Härle. Vicenza: Neri Pozza. Col. La quarta prosa, 2012.

BOMFIM, Gustavo. A. Ideias e formas na história do design: Uma investigação estética. João Pessoa: Universidade Federal da Paraíba, 1998.

COUTO, Rita M. S. Escritos sobre ensino de design no Brasil. Rio de Janeiro: Rio Book's, 2008. FREIRE, Paulo. Pedagogia da autonomia, saberes necessários à prática educativa. São Paulo: Paz e Terra, 1996.

GIBSON, James J. The ecological approach to visual perception. London: Lawrence Erlbaum Associates, Publisher, 1986.

GREENBERG, Clement. Estética doméstica - observações sobre a arte e o gosto. São Paulo: Cosac \& Naify, 2002.

HEIDEGGER, Martin. A origem da obra de arte. Lisboa: Edições 70, 1977.

LINGUAGENS Códigos e suas Tecnologias/ Secretaria de Educação Básica. - Brasília: Ministério da Educação, Secretaria de Educação Básica, 2008. v.1

LOTMAN, Yuri. La Semiosfera I, II, III. Madrid: Cátedra, 2000.

MACHADO, Irene. Escola de semiótica. São Paulo: Ateliê Editorial, 2003.

SANTOS, Milton. Por uma outra globalização. Rio de Janeiro/São Paulo: Record, 2000.

SANTOS, Milton. Técnica, espaço e tempo: globalização e meio-técnico científico informacional. São Paulo: Hucitec. 1997.

SERRES, Michel. Polegarzinha. Bertrand do Brasil/ Grupo Record. Rio de Janeiro: 2012.

SIMMEL, George. As grandes cidades e a vida do espírito in Mana- vol.11 no.2 Rio de Janeiro: 2005.

UEXKÜLL, Thure Von. A teoria da umwelt de Jakob von Uexküll. In Galáxia. São Paulo: Educ, p. 19-48, 2004.

VERGARA, Carlos. in A obra de Arte. Direção: Marcos Ribeiro. Brasil: 2009 (70 min).

WILLIAMS, Gareth. Telling Tales: Fantasy and fear in contemporary design. London, V\&A Publishing, 2009. 